\title{
Eco-friendly Synthesis of Cyclododecanone from Cyclododecatriene
}

\author{
Qi Feng, De-Kai Yuan, Dao-Quan Wang, Xiao-Mei Liang* , Jian-Jun Zhang, Jin-Ping Wu, \\ Fu-Heng Chen \\ Key Laboratory of Pesticide Chemistry and Application Technology, Department of Applied Chemistry, \\ China Agricultural University, Beijing, China \\ E-mail: *liangxiaomeim@yahoo.com.cn
}

Received June 21, 2011; revised July 23, 2011; accepted July 29, 2011

\begin{abstract}
An eco-friendly synthesis of cyclododecanone (CDON) from cyclododecatriene (CDT) is described. Selective epoxidation of CDT with hydrogen peroxide using hexadecyl trimethyl ammonium heteropolyphosphatotungstate $\left[\left(n-\mathrm{C}_{16} \mathrm{H}_{33} \mathrm{NMe}_{3}\right)_{3} \mathrm{PW}_{4} \mathrm{O}_{16}, \mathrm{HAHPT}\right]$ as catalyst and water as solvent followed by the hydrogenation on Raney nickel catalyst gave cyclododecanol (CDOL). The latter was oxidized with hydrogen peroxide using HAHPT as catalyst and a mixture of water and t-butanol as solvent to afford CDON. The total yield was $53.4 \%$ under the optimum reaction conditions.
\end{abstract}

Keywords: Eco-Friendly Synthesis, Cyclododecanone, Cyclododecatriene, Hexadecyl Trimethyl Ammonium Heteropolyphosphatotungstate

\section{Introduction}

Cyclododecanone (CDON) is an important precursor for laurolactam which is required for the production of Nylon-12 possessing distinct advantages as compared to Nylon-6 and Nylon-6,6 [1]. It is also useful for the synthesis of perfumes, such as muscone [2] and 1,15-pentade-canolide [3], pesticides [4] and pigments [5]. The synthesis of cyclododecanone and other cycloketones was first reported by Ruzicka and his co-workers from the rare-earth salts of dicarboxylic acids in 1926 [6]. However the yield reached only a few percent. Prelog and his co-workers prepared cyclododecanone in higher yield from dicarboxylic acid ester by acyloin synthesis in 1947 [7]. But anyhow, the preparation of CDON in large scale has not come true until the cyclododecatriene (CDT) can easily be produced from petrochemical product butadiene [8]. Synthetic methods of CDON from CDT are out- lined in Scheme 1 [9].

In this paper, we report an eco-friendly synthesis of cyclododecanone from 1,5,9-cis,trans,trans-CDT in three steps. Selective epoxidation of CDT gave epoxy- cyclododecadiene (ECDD), whose hydrogenation gave cyclododecanol (CDOL), which can be readily oxidized to obtain CDON. (Scheme 2).

\section{Experimental}

\subsection{General}

${ }^{1} \mathrm{H}$ NMR and ${ }^{13} \mathrm{C}$ NMR spectra were recorded in $\mathrm{CDCl}_{3}$ with a Brucker DPX 300 spectrometer using TMS as internal standard and ${ }^{31} \mathrm{P}$ NMR spectra recorded in a Varian IVOVA $300 \mathrm{MHz}$ NMR spectrometer in solid state and chemical shifts are given in ppm relative to $85 \%$ $\mathrm{H}_{3} \mathrm{PO}_{4}$. Cis,trans,trans-1,5,9-cyclododecatriene (CDT) (purity 99\%) was obtained from Alfa Aesar; sodium tungstate $\left(\mathrm{Na}_{2} \mathrm{WO}_{4} \cdot \mathrm{H}_{2} \mathrm{O}\right)$ was purchased from Chemical Reagents Co., Ltd., Guoyao Group, Beijing, China; 30\% $\mathrm{H}_{2} \mathrm{O}_{2}$ was purchased from Beihua Fine Chemicals Co., Ltd., Beijing ,China; aluminum nickel alloy was purchased from Beijing Pharmaceutical Co., Beijing, China; diethyl phthalate $(97 \%)$ was purchased from Tianhe Chemical Reagents Factory, Tianjin, China. All of reagents and solvents were used as received or were dried prior to use as needed.

\subsection{Analytic Method [10]}

The chromatographical analysis was carried out on a GC 9000 apparatus with a flame-ionization detector (FID), equipped with a computer system sample collection and 


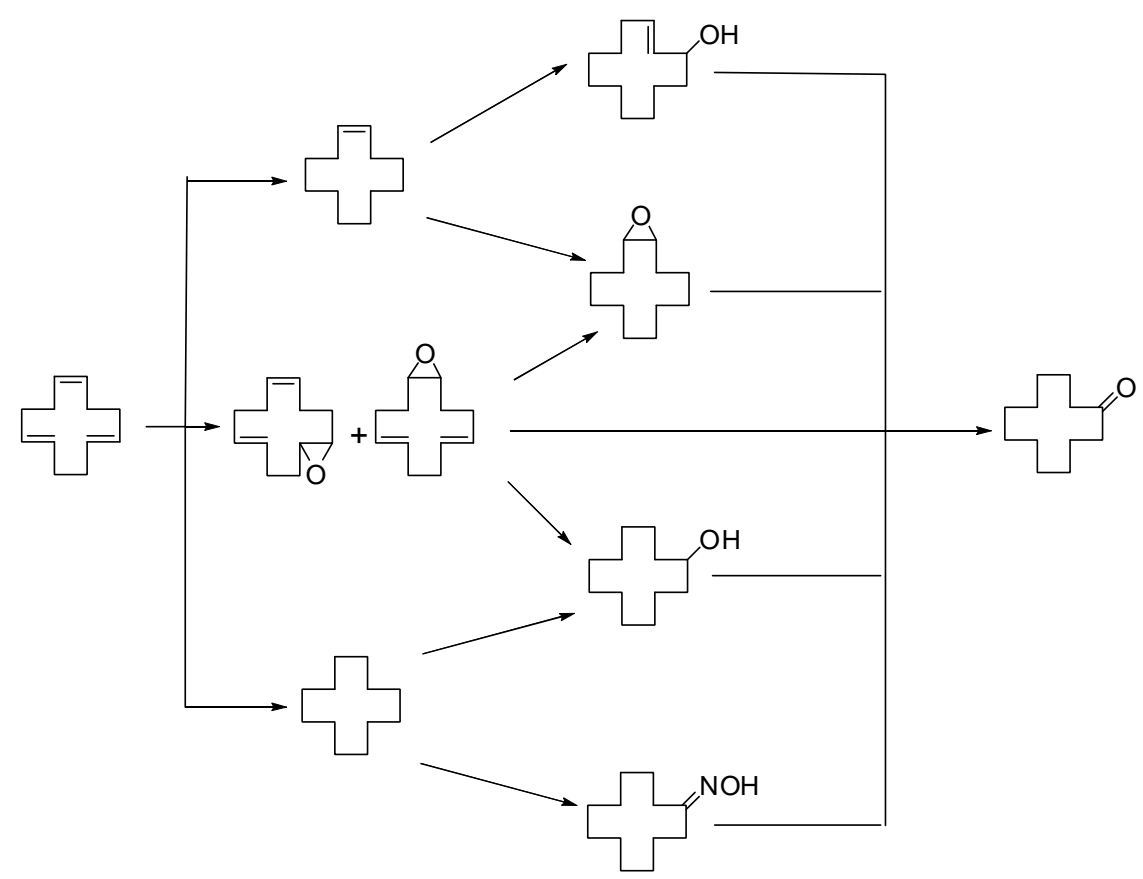

Scheme 1. Outline of synthetic routes for cyclododecanone from cyclododecatriene.
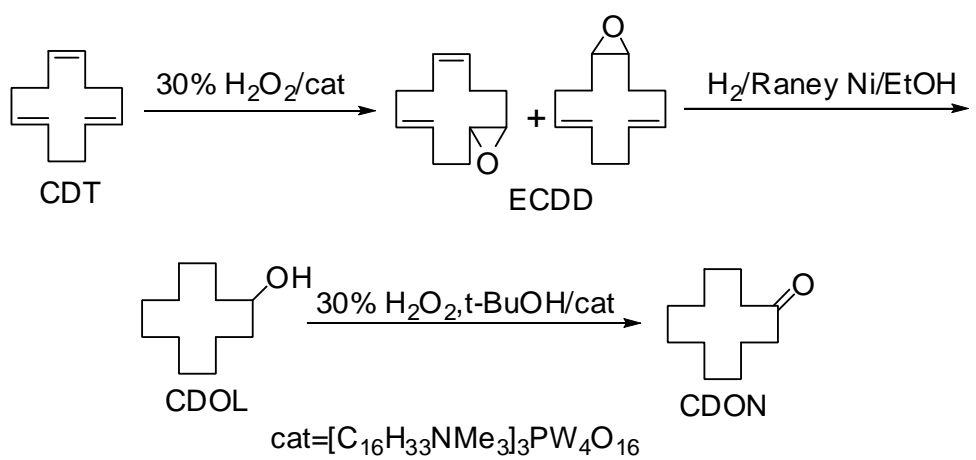

Scheme 2. Synthetic route of CDON from CDT in this paper.

data handling, and a OV-17 capillary column $(30 \mathrm{~m} \times$ $0.25 \mathrm{~mm}$ ). Injector temperature: $200^{\circ} \mathrm{C}$; detector temperature: $250^{\circ} \mathrm{C}$; column temperature $100^{\circ} \mathrm{C}$, hold $1 \mathrm{~min}$ and then programmed to $260^{\circ} \mathrm{C}$ at $20^{\circ} \mathrm{C} / \mathrm{min}$ and hold 3 min. The assignment of particular components was confirmed by comparison with standard compounds. The quantitative determination of the post-reaction mixtures was performed by:

1) The normalization method based on the peak area. A percentage content of determined component was calculated from equation:

$$
i \%=\frac{A i}{\sum A i} \times 100
$$

where $A i$ is peak area of determined component and $\sum A i$ the sum of peak area of all components.

2) The internal standard method using diethyl phtha- late. A percentage content of determined component was calculated from equation:

$$
i \%=F i \times \frac{A i}{A s} \times \frac{M s}{M i} \times 100
$$

where $F i$ is the correction coefficient of determined component, $A i$ the peak area of determined component, $A s$ the peak area of diethyl phthalate added to a sample, $M s$ the mass of diethyl phthalate added to a sample, and $M i$ the mass of analyzed sample.

\subsection{Preparation of Catalyst (HAHPT) [11,12]}

To a solution of $\mathrm{Na}_{2} \mathrm{WO}_{4} \cdot 2 \mathrm{H}_{2} \mathrm{O}(3.30 \mathrm{~g}, 10 \mathrm{mmol})$ in water $(20 \mathrm{~mL})$ was added $36 \% \mathrm{HCl}(1.97 \mathrm{~g}, 20 \mathrm{mmol})$ and pale yellow precipitate appeared immediately. Then $30 \% \mathrm{H}_{2} \mathrm{O}_{2}(8.65 \mathrm{~g}, 70 \mathrm{mmol})$ was added into the obtained 
mixture. After dissolution, $85 \% \mathrm{H}_{3} \mathrm{PO}_{4}(0.29 \mathrm{~g}, 2.5 \mathrm{mmol})$ and water $(10 \mathrm{~mL})$ were successively added. The resulting solution was stirred for $20 \mathrm{~min}$ at room temperature. A solution of $\mathrm{C}_{16} \mathrm{H}_{33}\left(\mathrm{CH}_{3}\right)_{3} \mathrm{NCl}(2.40 \mathrm{~g}, 7.5 \mathrm{mmol})$ in $\mathrm{ClCH}_{2} \mathrm{CH}_{2} \mathrm{Cl}(60 \mathrm{~mL})$ was added and stirred for another $1 \mathrm{~h}$. Resulting precipitate was filtered, washed with water until $\mathrm{pH}=5$, and dried under infrared light to give desired product HAHPT $4.45 \mathrm{~g}$ (yield 94.8\%).

\subsection{General Procedure for Epoxidation of CDT}

A mixture of weighed amount of HAHPT, CDT and $30 \%$ $\mathrm{H}_{2} \mathrm{O}_{2}$ was stirred at desired temperature for desired time. After completing reaction, the mixture was cooled to room temperature and the concentration of CDT, ECDD and other components was determined chromatographically by the normalization method. For each experiment on the effects of hydrogen peroxide amount, temperature, catalyst amount and reaction time the following magnitudes were calculated: the degree of conversion of CTD, the selectivity of transformation to ECDD in relation to consumed CTD. For experiment of epoxidation of CDT at the optimum reaction conditions the ECDD yield in relation to CTD introduced into reactor was given.

\subsection{General Procedure for Hydrogenation of ECDD}

Hydrogenation of ECDD was conducted by the method reported in [13] but using ethanol as the solvent instead of cyclohexane. A stainless steel autoclave having an inner volume of $200 \mathrm{~mL}$ and equipped with a stirrer (Weihai Chemical Appliance Co. Ltd., Sandong Province, China) was charged with nickel catalyst $(3.0 \mathrm{~mL}, \sim 1.5 \mathrm{~g})$ made by aluminum nickel alloy, ECDD (10 g) and ethanol $(100 \mathrm{~mL})$, and pressurized with hydrogen gas to 3.0 $\sim 3.5 \mathrm{MPa}$ at room temperature. The mixture was stirred at $100^{\circ} \mathrm{C}$ for $8 \mathrm{~h}$. After completing reaction, the mixture was cooled to room temperature. The crude product was weighed; content of CDOL was analyzed chromatographically by the normalization method and the CDOL yield in relation to ECDD was calculated.

\subsection{General Procedure for Oxidation of CDOL}

A mixture of weighed amount of HAHPT, CDOL, tbutanol and $30 \% \mathrm{H}_{2} \mathrm{O}_{2}$ was refluxed for desired time. After completing reaction, the mixture was cooled to room temperature and the concentration of CDOL, CDON and other components was determined by the internal standard method $(F i=0.67)$. For each experiment on the effects of catalyst amount and hydrogen peroxide amount the following magnitudes were calcu- lated: the degree of conversion of CDOL, the selectivity of transformation to CDON in relation to consumed CDOL. For experiment of oxidation of CDOL at the optimum reaction conditions the $\mathrm{CDON}$ yield in relation to CDOL introduced into reactor was given.

\section{Results and Discussion}

\subsection{Preparation of HAHPT}

Prepared HAHPT was characterized by ${ }^{31} \mathrm{P}$ NMR, $\delta: 5.2$, $-3.2,-12.9,-15.4,-25.1$. ([11]: 5.6, -0.8, -12.9, -27.7; [12]: $5.7-6.8,0.1,-3.9,-12.1,-24.0)$. Main absorption peaks were in agreement with those of the literature, which indicated that it contains desired active species.

\subsection{Epoxidation of CDT}

Among the oxidants, hydrogen peroxide is probably the best terminal oxidant after molecular oxygen with respect to environmental and economic considerations and also is one of the ideal oxidant in epoxidation of olefins, which might offer some advantages because 1) it generates only water as a by-product and 2) it has a high content of active oxygen species [14].

In this paper we used HAHPT [15] as catalyst for the epoxidation of CDT, which can be used for homogeneous catalytic epoxidation of olefins using aqueous hydrogen peroxide as oxidant. It could form soluble active species under the effect of hydrogen peroxide to lead to homogeneous catalytic epoxidation of olefins. When hydrogen peroxide was used up, the catalyst returned to its original structure and precipitated from the reaction system. Therefore this catalyst system possesses the advantages of both homogeneous and heterogeneous catalysts.

The products obtained from epoxidation of CDT contain ECDD, diepoxide and unreacted CDT. ECDD and diepoxid were separated and characterized by ${ }^{1} \mathrm{H}$ NMR.

For ECDD, $\delta$ : 1.10 - $1.35\left(\mathrm{~m}, 2 \mathrm{H}, \mathrm{CH}_{2}\right), 1.98-2.28(\mathrm{~m}$, $\left.10 \mathrm{H}, 5 \mathrm{CH}_{2}\right), 2.53(\mathrm{dt}, J=9.0 \mathrm{~Hz}, 2.2 \mathrm{~Hz}, \sim 0.63 \mathrm{H}$,

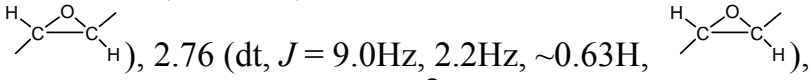

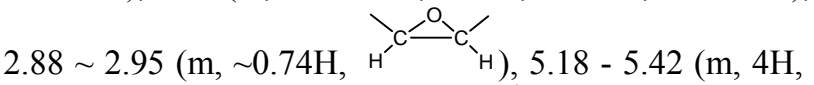
$2 \mathrm{CH}=\mathrm{CH})$. It can be seen from the ${ }^{1} \mathrm{H}$ NMR that ECDD is a mixture which contains $63 \%$ of 1,2-trans-epoxy-5, 9-cis,trans-cyclododecadiene and $37 \%$ of 1,2-cis-epoxy5,9-trans, trans-cyclododecadiene (See Scheme 2).

For diepoxide, $\delta$ : $1.12-1.35\left(\mathrm{~m}, 2 \mathrm{H}, \mathrm{CH}_{2}\right), 1.40-2.42$ $\left(\mathrm{m}, 10 \mathrm{H}, 5 \mathrm{CH}_{2}\right), 2.57-3.03\left(4 \mathrm{H}, 2 \stackrel{\mathrm{H}}{{ }_{\mathrm{C}}-\mathrm{C}_{\mathrm{H}}}\right), 5.30-5.52$ $(\mathrm{m}, 2 \mathrm{H}, \mathrm{CH}=\mathrm{CH})$. It is a mixture of 1,2 -cis-epoxy-5, 6-trans-epoxy-9-trans-cyclododecene and 1,2-trans- epoxy-5, 6- trans-epoxy-9-cis-cyclododecene. 
First of all, the effect of hydrogen peroxide amount was studied (Table 1). The reaction was performed at the temperature of $35^{\circ} \mathrm{C}$, at the molar ratio of $\mathrm{H}_{2} \mathrm{O}_{2}$ :catalyst $=200: 1$ and the reaction time $2 \mathrm{~h}$. It can be seen from Table 1 that with an increase of the molar ratio of $\mathrm{CDT} / \mathrm{H}_{2} \mathrm{O}_{2}$ from 3:1 to $2: 1$ caused an increase in CDT conversion from $27.5 \%$ to $42.0 \%$, but the ECDD selectivity was reduced from $96.7 \%$ to $92.2 \%$. Thus the molar ratio of $\mathrm{CDT} / \mathrm{H}_{2} \mathrm{O}_{2}=3: 1$ for the epoxidation of CDT is suitable. The unreacted CDT can be easily recovered.

Secondly the effect of temperature on the epoxidation of CDT was evaluated at the molar ratio of $\mathrm{H}_{2} \mathrm{O}_{2} / C D T /$ cat. $=600 / 200 / 1$ (Table 2). The results showed that temperature doesn't have a significant effect on CDT conversion and ECDD selectivity in the range of $45^{\circ} \mathrm{C}$ $65^{\circ} \mathrm{C}$ at the reaction time $0.5 \mathrm{~h}$. So the temperature of $55^{\circ} \mathrm{C}$ was selected for further study.

Then the effect of catalyst amount on the epoxidation of CDT was investigated at the temperature of $55^{\circ} \mathrm{C}$, at the molar ratio of CDT/ $\mathrm{H}_{2} \mathrm{O}_{2}=3: 1$ and the reaction time $1 \mathrm{~h}$. The results showed that the CDT conversion and ECDD selectivity almost remain unchanged at the molar ratio of cat/ $\mathrm{H}_{2} \mathrm{O}_{2} \geq 1 / 1000$ (Table 3).

The effect of reaction time on the epoxidation of CDT was not studied for the CDT conversion and ECDD selectivity are almost unchangeable when reaction time was prolonged from $1 \mathrm{~h}$ to $2 \mathrm{~h}$.

Under the optimum reaction conditions the epoxidation of CDT was performed repeatedly for five times (Table 4). The average yield of ECDD was $61.8 \%$

In addition, the recycle of catalyst was investigated in the epoxidation of CDT (Table 5). The results showed that the recycled catalyst had high activity in all runs, namely CDT conversion kept the same level, and ECDD selectivity was still high after three recycles.

Table 1. The effect of $\mathrm{H}_{2} \mathrm{O}_{2}$ amount on the epoxidation of CDT.

\begin{tabular}{cccc}
\hline $\begin{array}{c}\mathrm{CDT} / \mathrm{H}_{2} \mathrm{O}_{2} \\
(\mathrm{~mol} / \mathrm{mol})\end{array}$ & $\begin{array}{c}\text { Reaction time } \\
(\mathrm{h})\end{array}$ & $\begin{array}{c}\text { CDT conversion } \\
(\mathrm{mol} \%)\end{array}$ & $\begin{array}{c}\text { ECDD } \\
\text { selectivity } \\
(\mathrm{mol} \%)\end{array}$ \\
\hline $600 / 200$ & 2 & 27.5 & 96.7 \\
$500 / 200$ & 2 & 34.1 & 93.6 \\
$400 / 200$ & 2 & 42.0 & 92.2 \\
\hline
\end{tabular}

Table 2. The effect of temperature on the epoxidation of CDT.

\begin{tabular}{cccc}
\hline $\begin{array}{c}\text { Temperature } \\
\left({ }^{\circ} \mathrm{C}\right)\end{array}$ & $\begin{array}{c}\text { Reaction time } \\
(\mathrm{h})\end{array}$ & $\begin{array}{c}\text { CDT conversion } \\
(\mathrm{mol} \%)\end{array}$ & $\begin{array}{c}\text { ECDD } \\
\text { selectivity } \\
(\mathrm{mol} \%)\end{array}$ \\
\hline 35 & 3 & 27.9 & 96.7 \\
45 & 0.5 & 26.9 & 98.5 \\
55 & 0.5 & 27.0 & 96.7 \\
65 & 0.5 & 26.6 & 97.2 \\
\hline
\end{tabular}

Table 3. The effect of catalyst amount on the epoxidation of CDT.

\begin{tabular}{ccc}
\hline $\begin{array}{c}\mathrm{Cat} . / \mathrm{H}_{2} \mathrm{O}_{2} \\
(\mathrm{~mol} / \mathrm{mol})\end{array}$ & $\begin{array}{c}\text { CDT conversion } \\
(\mathrm{mol} \%)\end{array}$ & $\begin{array}{c}\text { ECDD selectivity } \\
(\mathrm{mol} \%)\end{array}$ \\
\hline $1 / 300$ & 27.3 & 95.8 \\
$1 / 400$ & 27.7 & 95.0 \\
$1 / 1000$ & 27.9 & 95.0 \\
$1 / 1500$ & 23.8 & 97.3 \\
$1 / 2000$ & 23.2 & 83.3 \\
\hline
\end{tabular}

Table 4. Epoxidation of CDT at the optimum reaction conditions*.

\begin{tabular}{ccccc}
\hline & Recovered CDT/g & Residue/g & $\begin{array}{c}\text { ECDD content of } \\
\text { the residue/\% }\end{array}$ & $\begin{array}{c}\text { ECDD yield } \\
/ \%\end{array}$ \\
\hline 1 & 19.60 & 11.94 & 76.1 & 64.4 \\
2 & 18.82 & 10.58 & 72.1 & 51.0 \\
3 & 20.32 & 10.04 & 82.5 & 62.2 \\
4 & 21.15 & 9.28 & 87.9 & 65.5 \\
5 & 21.16 & 10.40 & 78.3 & 65.7 \\
\hline
\end{tabular}

*Experimental conditions: CDT $32.44 \mathrm{~g}(0.2 \mathrm{~mol}) / 30 \% \mathrm{H}_{2} \mathrm{O}_{2} 6.20 \mathrm{~mL}(0.06$ $\mathrm{mol} / \mathrm{cat}$. (HAHPT) $0.11 \mathrm{~g}=3000 / 1000 / 1(\mathrm{~mol} / \mathrm{mol} / \mathrm{mol})$; reaction temperature $55^{\circ} \mathrm{C}$; and reaction time $1 \mathrm{~h}$. After completing reaction, the mixture was distilled under the reduced pressure and unreacted CDT was recovered. The ECDD in the residue was determined by gas chromatographic analysis. ECDD yield was calculated according to the formula:

$$
Y=\frac{R \times E C C \times 162.3}{(32.44-R C) \times 178.3} \times 100
$$

In which $Y$ is the ECDD yield, $R$ is the weight of the residue after distillation, $E C C$ is the ECDD content in the residue, $R C$ is the weight of the recovered CDT, "162.3" is Mol. Wt. of CDT and "178.3" is Mol. Wt. of ECDD.

Table 5. Recycle of catalyst in the epoxidation of CDT*

\begin{tabular}{ccc}
\hline Catalyst & CDT conversion (mol \%) & ECDD selectivity (mol \%) \\
\hline Fresh & 27.9 & 95.0 \\
Recycle 1 & 26.8 & 91.9 \\
Recycle 2 & 26.7 & 85.9 \\
Recycle 3 & 29.2 & 83.4 \\
\hline
\end{tabular}

*Experimental procedure: A mixture of CDT $3.24 \mathrm{~g}(20 \mathrm{mmol}), 30 \% \mathrm{H}_{2} \mathrm{O}_{2}$ $0.62 \mathrm{~mL}(6 \mathrm{mmol})$ and HTAPT $0.0112 \mathrm{~g}$ was stirred at $55^{\circ} \mathrm{C}$ for $1 \mathrm{~h}$. After the catalyst was precipitated from the reaction medium, the mixture was stirred for another $2 \mathrm{~h}$ at room temperature to make the procedure completed. The precipitate (recovered catalyst) was filtered and used for next recycle.

\subsection{Hydrogenation of ECDD}

Several patents $[13,16]$ described the preparation of CDOL from ECDD by the hydrogenation in the presence of a nickel or palladium catalyst, which is a kind of clean synthesis of alcohols from epoxy compounds.

In this paper we selected Raney nickel as catalyst and harmless ethanol as solvent for the hydrogenation of ECDD. The same product was given from the hydrogenation of ECDD, a mixture of 1,2-epoxy-5-cis-9-transcyclododecadiene and 1,2-epoxy-5-trans-9-trans-cyclo- 
dodecadiene (see Scheme 2). The result (Table 6) showed that the average yield of hydrogenation of ECDD was $92.3 \%$ and the highest yield is $94.9 \%$ which is comparable with the yield reported in ref. [13]. In addition, this procedure is greener due to the use of harmless ethanol as solvent instead of cyclohexane employed in ref. [13].

Crude product was purified and characterized by ${ }^{1} \mathrm{H}$ $\mathrm{NMR}$ and ${ }^{13} \mathrm{C}$ NMR.

${ }^{1} \mathrm{H}$ NMR, $\delta: 1.34-1.47\left(\mathrm{~m}, 21 \mathrm{H}, 9 \mathrm{CH}_{2}+(\right.$ trans $) \underline{\mathrm{HC}}-$ $\mathrm{C}(\mathrm{OH})-\mathrm{C} \underline{\mathrm{H}}($ trans $)+\mathrm{CH}-\mathrm{O} \underline{\mathrm{H}})), 1.61-1.71$ (m, 2H, (cis)HC-C(OH)-CH(cis)), $3.82-3.87$ (m, 1H, CH-OH).

${ }^{13} \mathrm{C}$ NMR, $\delta: 21.00,23.32,23.41,23.88,24.27,32.54$, 69.23 ( $\underline{\mathrm{CH}}-\mathrm{OH})$.

\subsection{Oxidation of CDOL}

Various oxidizing agents have been used for the oxidation of CDOL to CDON [17-24]. Hydrogen peroxide is probably the best oxidant after molecular oxygen for the oxidation of alcohols. However, oxidation of alcohols by hydrogen peroxide needs a long reaction time and the use of catalyst. Recently Zhang and co-workers [11] reported that not only olefins could be oxidized to epoxides but also secondary alcohols could be oxidized to ketones with aqueous hydrogen peroxide as oxidant in the presence of HAHPT under solvent-free conditions except water. In this paper we selected HAHPT as catalyst for the oxidation of CDOL to CDON using aqueous hydrogen peroxide as oxidant owing to its advantages mentioned above.

We carried out the oxidation of CDOL under the conditions reported in ref [11] just in a routine reactor instead of in the sealed pressure glass tube. Unfortunately a great quantity of foam took place during the reaction and the oxidation of CDOL can't proceed. The problem was overcome by using t-butanol as defoamer, namely a mixture of t-butanol and water as solvent. Optimum molar ratio of $\mathrm{CDOL} / \mathrm{t}$-butanol is 1:0.75. Following the solution of foaming, the effect of catalyst and hydrogen peroxide amount on the oxidation of CDOL was investigated. The results showed that with decreasing the molar ratio of cat/CDOL from $1 / 200$ to $1 / 1000$, the $\mathrm{CDON}$ selectivity was increased from $92.8 \%$ to $96.5 \%$ and CDOL conversion almost kept the same level. However,

Table 6. Hydrogenation of ECDD.

\begin{tabular}{cccc}
\hline & Crude product/g & Content of CDOL/\% & CDOL yield/\% \\
\hline 1 & 10.13 & 93.4 & 91.5 \\
2 & 10.07 & 95.0 & 92.5 \\
3 & 10.71 & 91.6 & 94.9 \\
4 & 10.76 & 86.8 & 90.3 \\
\hline
\end{tabular}

the molar ratio of cat/CDOL further decreased to $1 / 2000$, both the CDOL conversion and CDON selectivity were decreased (Table 7(1)).

When the molar ratio of $\mathrm{CDOL} / \mathrm{H}_{2} \mathrm{O}_{2}$ decreased from $1: 3$ to $1: 2$ and the molar ratio of cat/CDOL kept 1/1000, the CDOL conversion and CDON selectivity kept unchangeable (100\% and $96.4 \%)$ if reaction time extended to $5 \mathrm{~h}$. With further decreasing the molar ratio of cat /CDOL to $1 / 1500$ and $1 / 2000$, both the CDOL conversion and CDON selectivity decreased although reaction time extended to $7-10 \mathrm{~h}$ (Table $\mathbf{7 ( 2 )}$ ). The optimum molar ratio of cat/CDOL/t-BuOH/ $\mathrm{H}_{2} \mathrm{O}_{2}$ was $1 / 1000 / 750 /$ 2000.

Under the optimum reaction conditions the oxidation of CDOL was performed repeatedly for five times (Table 8). The average yield of CDON was $93.6 \%$.

Crude product was purified and characterized by ${ }^{1} \mathrm{H}$ $\mathrm{NMR}$ and ${ }^{13} \mathrm{C}$ NMR.

${ }^{1} \mathrm{H}$ NMR, $\delta: 1.24$ - $1.33\left(\mathrm{~m}, 14 \mathrm{H}, 7 \mathrm{CH}_{2}\right), 1.67$ - 1.76 (m, $\left.4 \mathrm{H}, \mathrm{C}_{2} \mathrm{CH}_{2}-\mathrm{CO}-\mathrm{CH}_{2} \underline{\mathrm{C}}_{2}\right), 2.44-2.48$ (m, 4H, $\mathrm{CH}_{2}-\mathrm{CO}-\mathrm{CH}_{2}$ ).

${ }^{13} \mathrm{C}$ NMR, $\delta: 22.23,22.38,24.08,24.47,24.60,40.18$, $212.41(\mathrm{C}=\mathrm{O})$.

\section{Conclusions}

An eco-friendly three-step procedure for the synthesis of CDON from CDT was developed: HAHPT possessing both homogeneous and heterogeneous properties was selected as catalyst, hydrogen peroxide as oxidant and water as solvent for the selective epoxidation of CDT.

Table 7. (1) The effect of catalyst amount on the oxidation of $\mathrm{CDOL}$ at the molar ratio of $\mathrm{CDOL} / \mathrm{t}-\mathrm{BuOH} / \mathrm{H}_{2} \mathrm{O}_{2}=$ $1 / 0.75 / 3$. (2) The effect of catalyst amount on the oxidation of $\mathrm{CDOL}$ at the molar ratio of $\mathrm{CDOL} / \mathrm{t}-\mathrm{BuOH} / \mathrm{H}_{2} \mathrm{O}_{2}=$ 1/0.75/2.

\begin{tabular}{cccc}
\hline $\begin{array}{c}\text { Cat./ CDOL } \\
(\mathrm{mol} / \mathrm{mol})\end{array}$ & $\begin{array}{c}\text { Reaction time } \\
(\mathrm{h})\end{array}$ & $\begin{array}{c}\text { CDOL } \\
\text { conversion } \\
(\mathrm{mol} \%)\end{array}$ & $\begin{array}{c}\text { CDON } \\
\text { selectivity } \\
(\mathrm{mol} \%)\end{array}$ \\
\hline $1 / 200$ & 3 & 100 & 92.8 \\
$1 / 400$ & 3 & 100 & 94.6 \\
$1 / 1000$ & 3 & 100 & 96.5 \\
$1 / 2000$ & 3 & 94.8 & 95.9 \\
\hline
\end{tabular}

\begin{tabular}{cccc}
\hline $\begin{array}{c}\text { Cat./ CDOL } \\
(\mathrm{mol} / \mathrm{mol})\end{array}$ & $\begin{array}{c}\text { Reaction time } \\
(\mathrm{h})\end{array}$ & $\begin{array}{c}\text { CDOL } \\
\text { conversion } \\
(\mathrm{mol} \%)\end{array}$ & $\begin{array}{c}\text { CDON } \\
\text { selectivity } \\
(\mathrm{mol} \%)\end{array}$ \\
\hline $1 / 1000$ & 5 & 100 & 96.4 \\
$1 / 1500$ & 5 & 100 & 93.5 \\
$1 / 2000$ & 7 & 98.0 & 95.7 \\
$1 / 2000$ & 10 & 100 & 91.2 \\
\hline
\end{tabular}


Table 8. Oxidation of CDOL at the optimum reaction conditions*.

\begin{tabular}{ccccc}
\hline & CDOL conversion/\% & Crude product $/ \mathrm{g}$ & CDON content of crude product $/ \%$ & CDON yield/\% \\
\hline 1 & 100 & 5.40 & 95.0 & 94.0 \\
2 & 100 & 5.42 & 94.1 & 94.3 \\
3 & 100 & 5.39 & 94.5 & 93.8 \\
4 & 5.40 & 94.0 & 93.0 \\
5 & 100 & 5.36 & 94.6 & 93.6 \\
\hline
\end{tabular}

*Experimental conditions: HAHPT $56 \mathrm{mg}(0.03 \mathrm{mmol})$, CDOL $5.52 \mathrm{~g}(0.03 \mathrm{~mol}), \mathrm{t}-\mathrm{BuOH} 2.0 \mathrm{~mL}(0.00225 \mathrm{~mol})$, and $30 \% 6.20 \mathrm{~mL} \mathrm{H} \mathrm{O}_{2}(0.060 \mathrm{~mol})$, namely the molar ratio of cat/CDOL/t-BuOH/ $\mathrm{H}_{2} \mathrm{O}_{2}$ was 1/1000/750/2000; reaction temperature: reflux; and reaction time $5 \mathrm{~h}$. After the completion of reaction, water 25 $\mathrm{mL}$ was added. The mixture was stirred to room temperature. Filtered to give white solid which was dried, weighed and analyzed.

HAHPT can be recovered and reused. 2. Compared to previous reported methods, present procedure for the hydrogenation of ECDD is greener due to the use of harmless ethanol as solvent instead of cyclohexane. 3. Compared to previous reported oxidation of secondary alcohol employing hydrogen peroxide as oxidant in a sealed pressure glass tube, present oxidation of CDOL employing hydrogen peroxide as oxidant can be come true in a routine reactor due to the use of t-butanol as defoamer.

\section{References}

[1] S. S. Mahajan, M. M. Sharma and T. Sridhar, "Uncatalyzed Oxidation of 1,5,9-Cyclododecatriene with Molecular Oxygen," Industrial and Engineering Chemistry Research, Vol. 46, No. 10, 2007, pp. 3057-3062. doi:10.1021/ie061072n

[2] H. Rademacher and H.-W. Voges, "Method for Preparing Lactams Having 8 to 15 Carbon Atoms from the Corresponding Oximes," US Patent No. 4689412, 1987.

[3] Z.-F. Xie and K. Sakai, "Construction of Medium- and Large-Sized Cyclic .Beta.-Keto Esters (or Nitriles) via One-Pot Three-Carbon Ring Expansion of Carbocyclic .Beta.-Keto Esters and Its Application to the Synthesis of (-)-Muscone," The Journal of Organic Chemistry, Vol. 55, No. 3, 1990, pp. 820-826. doi:10.1021/jo00290a009

[4] P. Dowd and S.-C. Choi, "Free Radical Ring Expansion and Rearrangement of Large Carbocyclic Rings," Tetrahedron Letters, Vol. 32, No. 5, 1991, pp. 565-568. doi:10.1016/S0040-4039(00)74828-3

[5] D. S. Wang, D. Q. Wang and C. H. Zhou, "Title of This Paper," Acta Chimica Sinica, Vol. 53, No. *, 1995, pp. 909-915.

[6] S. Stanchev, B. Milenkov and M. Hesse, "A Short Synthesis of 15-Pentadecanolide," Tetrahedron Letters, Vol. 34, No. 38, 1993, pp. 6107-6108. doi:10.1016/S0040-4039(00)61741-0

[7] Y. H. Dong, X. M. Liang, H. Z. Yuan, et al., "Potential Green Fungicide: 16-Oxo-1-Oxa-4-Azoniacyclohexadecan-4-Ium Tetrafluoroborate," Green Chemistry, Vol. 10, No. 9, 2008, pp. 990-994. doi:10.1039/b805797d

[8] J. X. Huang, X. M. Liang, J. J. Zhang, et al., "Fungicidal
Activity of 12-Propoxyimino-1, 15-Pentadecanlactam on Selected Crops," Crop Protection, Vol. 28, No. 11, 2009, pp. 947-951. doi:10.1016/j.cropro.2009.07.017

[9] H. H. Wasserman, G. C. Rodgers and D. D. Keith, "Metacycloprodigiosin, a Tripyrrole Pigment from Streptomyces Longisporus Rubber," Journal of the American Chemical Society, Vol. 91, No. 5, 1969, pp. 1263-1264. doi:10.1021/ja01033a065

[10] H. H. Wasserman, D. D. Keith and J. Nadelson, "Synthesis of Metacycloprodigiosin," Journal of the American Chemical Society, Vol. 91, No. 5, 1969, pp. 1264-1265. doi:10.1021/ja01033a066

[11] L. Ruzicka, M. Stoll and H. Schinz, "Zur Kenntnis des Kohlenstoffringes II. Synthese der carbocyclischen Ketone vom Zehnerbis zum Achtzehnerring," Helvetica Chemical Acta, Vol. 9, No. 1, 1926, pp. 249-264. doi:10.1002/hlca.19260090130

[12] V. Prelog, L. Frenkiel, M. Kobelt, et al., "Zur Kenntnis des Kohlenstoffringes. Ein Herstellungsverfahren für Vielgliedrige Cyclanone," Helvetica Chemical Acta, Vol. 30, No. 6, 1947, pp. 1741-1749. doi:10.1002/hlca.19470300637

[13] G. Wilke and H. Muller, "Title of This Patent," DE No. 1043329, 1958.

[14] H. Weber, W. Ring, U. Hochmuth, et al., "Zur Bildungsweise von cis,trans,trans-Cyclododecatrien-(1,5,9) Mittels Titanhaltiger Ziegler-Katalysatoren," Justus Liebigs Annalen der Chemie, Vol. 681, No. 1, 1965, pp. 10-20. doi:10.1002/jlac.19656810103

[15] X. J. Yan, Q. Feng, S. H. Jin, et al., "Title of This Paper," Fine Chemical Intermediates, Vol. 38, No. 2, 2008, pp. $1-8$.

[16] J. Lebbe, "Quantitative Analysis," In: J. Tranchani, Ed., Practical Manual of Gas Chromatography, Elsevier, New York, 1969, pp. 257-286.

[17] S. J. Zhang, S. Gao, Z. W. Xi, et al., "Solvent-Free Oxidation of Alcohols Catalyzed by an Efficient and Reusable Heteropolyphosphatotungstate," Catalysis Communications, Vol. 8, No. 3, 2007, pp. 531-534. doi:10.1016/j.catcom.2006.02.020

[18] X. G. Yang, S. J. Zhang, M. Li, et al., "Synthesis of MgAPO-11 Molecular Sieves and the Catalytic Performance of Pt/MgAPO-11 for $n$-Dodecane Hydroisomerization," Chinese Journal of Catalysis, Vol. 27, No. 1, 2006, 
pp. 50-54. doi:10.1016/S1872-2067(06)60055-7

[19] N. Kuroda, T. Matsuzaki and M.Yamanaka, "Method of Reducing Epoxidized Organic Compound with Hydrogen," WO/2000026165, 2000.

[20] B. S. Lane and K. Burgess, "Metal-Catalyzed Epoxidations of Alkenes with Hydrogen Peroxide," Chemical Reviews, Vol. 103, No. 7, 2003, pp. 2457-2473. doi: $10.1021 / \mathrm{cr} 020471 \mathrm{z}$

[21] N. Mizuno, K. Yamaguchi and K. Kamata, "Epoxidation of Olefins with Hydrogen Peroxide Catalyzed by Polyoxometalates," Coordination Chemical Reviews, Vol. 249, No. 17-18, 2005, pp. 1944-1956. doi:10.1016/j.ccr.2004.11.019

[22] Z. W. Xi, N. Zhou, Y. Sun, et al., "Reaction-Controlled Phase-Transfer Catalysis for Propylene Epoxidation to Propylene Oxide," Science, Vol. 292, No. 5591, 2001, pp. 1139-1141. doi:10.1126/science.292.5519.1139

[23] K. L. Li, N. Zhou and Z. W. Xi, "Title of This Paper," Chinese Journal of Catalysis, Vol. 23, No. 2, 2002, pp. 125-126.

[24] X. G, Yang, S. J. Zhang, M. Li, et al., "Title of This Paper," Name of Journal, Vol. 27, No. 1, 2006, pp. 50-54,

[25] N.Kuroda and T.Nakamura, JP2001302570, 2001.

[26] T. Matsuzaki, Y. Nakamura and T. Manabe, "Method for Producing Cycloalkanol and Cycloalkanone," JP No. 2002161057, 2002.

[27] T .Matsuzaki, Y. Nakamura and O. Yamazaki, "Process for the Production of a Cycloalkanone and/or a Cycloalkanol," JP No. 2002114732, 2002.

[28] T. Matsuzaki, Y. Nakamura and O. Yamazaki, "Method for Producing Cycloalkanol and Cycloalkanone," JP No. 2002047220, 2002.
[29] P. Mueller and J. Godoy, "Catalyzed Oxidation of Alcohols and Aldehydes with Iodosylbenzene," Tetrahedron Letters, Vol. 22, No. 25, 1981, pp. 2361-2364. doi:10.1016/S0040-4039(01)82906-3

[30] M. E. Krafft and B. Zorc, "Oxidation of Secondary Alcohols Using Raney Nickel," The Journal of Organic Chemistry, Vol. 51, No. 26, 1986, pp. 5482-5484. doi:10.1021/jo00376a099

[31] Y. Kurusu and Y.Masuyama, "Catalysis by Tetrabromooxomolybdate(V) Complex: Oxidation of Olefins and Alcohols with $t$-Butyl Hydroperoxide," Polyhedron, Vol. 5, No. 1-2, 1986, pp. 289-296. doi:10.1016/S0277-5387(00)84924-4

[32] T. Morimoto, M. Hirano, H. Ashiya, et al., "Oxidation of Aliphatic Secondary and Benzylic Alcohols to Carbonyl Compounds by Peracetic Acid in the Presence of Sodium Bromide in Acetic Acid," Bulletin of the Chemical Society of Japan, Vol. 60, No. 11, 1987, pp. 4143-4144. doi:10.1246/bcsj.60.4143

[33] T. Morimoto, M. Hirano, Y. Aikawa, et al., ““Title of This Paper," Journal of the Chemical Society, Perkin Transactions 1, No. 8, 1988, pp. 2423-4.

[34] T. Nishiguchi and F.Asano, "Oxidation of Alcohols by Metallic Nitrates Supported on Silica Gel," The Journal of Organic Chemistry, Vol. 54, No. 7, 1989, pp. 15311535. doi:10.1021/jo00268a011

[35] M. Yamaguchi, T. Takata and T. Endo, "Oxidation of Cycloalkanols to the Corresponding Cycloalkanones with Chlorine in the Presence of Nitroxide Radical as a Mediator," Bulletin of the Chemical Society of Japan, Vol. 63, No. 3, 1990, pp. 947-949. doi:10.1246/bcsj.63.947

[36] S. Furusaki, M. Matsuda and M. Hida, "Production of Cyclododecanone," JP No. 03115247, 1991. 